\title{
Food intolerance: a community survey
}

\author{
BY M. L. BURR \\ MRC Epidemiology Unit, 4 Richmond Road, Cardiff CF2 $3 A S$
}

AND T. G. MERRETT

\author{
RAST Allergy Unit, Benenden Chest Hospital, Benenden, Cranbrook, Kent
}

(Received 10 September 1982 - Accepted 25 October 1982)

\begin{abstract}
1. A questionnaire inquiring about food intolerance was sent to a random sample of the electorate in a small South Wales town. Replies were received from 170 men and 305 women, the response rates being 87 and $93 \%$ respectively.

2. Adverse effects of some food were reported by $19 \%$ of men and $26 \%$ of women, or 14 and $18 \%$ respectively if minor digestive symptoms are excluded. Certain foods were thought to cause non-abdominal symptoms by $4 \%$ of men and $10 \%$ of women, and vomiting, diarrhoea or abdominal pain by $11 \%$ of men and $10 \%$ of women.

3. Plasma IgE was measured in a random subset of ninety-nine women and found to be significantly lower in those with major symptoms than in the rest. This suggests that allergy is probably not a common cause of food intolerance.
\end{abstract}

In view of the current interest in food intolerance it is important to know its prevalence in the general population. A recent survey, conducted on University teaching staff, led to the suggestion that approximately one-third of the population suffers from adverse reactions to food (Bender \& Matthews, 1981). Since the subjects of this survey were not entirely typical of the general population, and their response-rate was rather low $(56 \%)$, it seemed worthwhile to conduct a survey on a random sample of the electorate in a small South Wales town to see whether similar findings emerged.

\section{METHODS}

Random samples were taken from the electoral register of a small town (population 6000) in South Wales, yielding 196 men and 328 women after eliminating those who had moved out of the area. The disparity between the numbers of men and women arose intentionally because more women were needed for a nutritional survey which took place concurrently. The subjects were sent a short questionnaire asking whether any foods made them ill; if so, which foods and in what way. They were also asked whether they had ever suffered from asthma or hay fever. Subjects who did not reply were sent a second questionnaire and visited if they still failed to reply. Blood was taken from a random subsample of the women for plasma IgE estimation using a fast double-antibody-separation technique (Merrett \& Merrett, 1978).

\section{RESULTS}

Of the 524 subjects who received questionnaires, 170 men and 305 women replied, giving response rates of 87 and $93 \%$ respectively. Table 1 shows the numbers of subjects who reported symptoms due to food. Non-abdominal symptoms were reported by six men and twenty-nine women ( 4 and $10 \%$ respectively), the commonest being headache or migraine. Vomiting, diarrhoea or abdominal pain were attributed to food by nineteen men and thirty-two women (11 and $10 \%$ respectively), while minor digestive symptoms (e.g. nausea, abdominal discomfort, flatulence, indigestion, constipation) occurred in a further ten men and twenty-three women ( 6 and $8 \%$ respectively). The over-all prevalence of food-related 
Table 1. Symptoms attributed to foods in 112 of 475 subjects responding to a questionnaire relating to food intolerance

(Values in parentheses indicate percentage of total)

\begin{tabular}{lll}
\hline \multicolumn{1}{c}{ Symptoms } & Men & Women \\
\hline Headache, migraine & 3 & 12 \\
Skin symptoms & 1 & 11 \\
Mouth ulcers, sore throat & 1 & 4 \\
Giddiness, shaking, fainting & 1 & 1 \\
Aching joints & 0 & $29(10)$ \\
All with non-abdominal & $6(4)$ & $32(10)$ \\
$\quad$ symptoms & $19(11)$ & $56(18)$ \\
$\quad$ Vomiting, diarrhoea, & $23(14)$ & $23(8)$ \\
$\quad$ abdominal pain & $10(6)$ & $226(74)$ \\
Any of the above symptoms & $137(81)$ & 305 \\
Minor digestive symptoms & 170 & \\
$\quad$ only symptom & No. of subjects who responded & \\
\hline
\end{tabular}

syniptoms was 19 and $26 \%$ in men and women respectively, or 14 and $18 \%$ if the minor digestive symptoms are excluded.

The foods involved are listed in Table 2. There are thirty-seven rather than thirty-three persons classified under 'minor digestive symptoms only' since in four people one food caused minor symptoms and another food caused major symptoms. Migraine or headache was attributed to cheese in ten subjects and to chocolate in nine. The other main cause of non-abdominal symptoms was fruit (mainly oranges, bananas and tomatoes), associated with migraine, rashers and mouth ulcers in three subjects each and with a sore throat in one. Abdominal symptoms were attributed to a wider range of foods, onions being one of those most frequently mentioned.

The food-intolerant subjects were compared with the other subjects to see whether they were more liable to hay fever or asthma. Those who complained only of minor digestive symptoms were not included in the food-intolerant group since their symptoms seemed less likely to have an allergic basis. Of the food-intolerant men, $17 \%$ reported a history of asthma or hay fever at some time in their lives as did $12 \%$ of the other men; the corresponding values for women were 27 and $19 \%$ respectively. In neither case was the difference statistically significant.

Total plasma IgE concentrations were compared in the sub-sample of women from whom blood was taken. Sixteen women with food intolerance (other than minor digestive symptoms) had a geometric mean IgE of $20.0 \mathrm{u} / \mathrm{ml}$ compared with $29.3 \mathrm{u} / \mathrm{ml}$ in eighty-three other women. The difference was statistically significant $(P<0.05)$ and is in the opposite direction from that which would be expected if food intolerance were associated with allergy.

\section{DISCUSSION}

There are few estimates of the prevalence of food intolerance in the general population. Bleumink (1970) stated that values range from 1 to $40 \%$, and considered that true food allergy occurred in under $0.5 \%$. Bender \& Matthews (1981) obtained a history of adverse reactions to food in $33 \%$ of their subjects. But these were University teaching staff, who are not representative of the general population. The present survey was undertaken in a random sample of the electorate of a small town, and the response rates obtained $(87 \%$ 
Table 2. Foods thought to cause symptoms in 112 of 475 subjects responding to a questionnaire relating to food tolerance

\begin{tabular}{lcccc}
\hline \hline & & $\begin{array}{c}\text { Vomiting, } \\
\text { diarthoea } \\
\text { abdominal } \\
\text { pain }\end{array}$ & $\begin{array}{c}\text { Minor } \\
\text { fon-abdomina } \\
\text { symptoms } \\
\text { only }\end{array}$ & $\begin{array}{c}\text { Any } \\
\text { symptom }\end{array}$ \\
\hline Cheese & 11 & 2 & 8 & 20 \\
Chocolate & 10 & 1 & 2 & 12 \\
Meat, offal & 4 & 11 & 2 & 16 \\
Fruit & 10 & 9 & 8 & 26 \\
Onion, garlic & 2 & 9 & 10 & 21 \\
Other vegetables & 2 & 10 & 6 & 18 \\
Shellfish & 4 & 8 & 0 & 10 \\
Fish & 2 & 3 & 2 & 7 \\
Alcohol & 4 & 2 & 0 & 4 \\
Tea, coffee & 0 & 4 & 0 & 4 \\
Egg & 1 & 3 & 2 & 6 \\
Fats, fried food & 0 & 5 & 13 & 18 \\
Milk & 1 & 0 & 4 & 5 \\
Spice, curry & 2 & 3 & 1 & 6 \\
Other foods & 1 & 3 & 4 & 7 \\
No. of subjects who responded & 35 & 51 & 37 & 112 \\
\hline \hline
\end{tabular}

for men, $93 \%$ for women) were reasonably high. The results suggest that approximately one-fifth of the men and one-quarter of the women attribute some adverse effects to foods; if minor digestive symptoms are excluded, the prevalence of reported food intolerance is $14 \%$ in men and $18 \%$ in women. The higher values reported by Bender \& Matthews (1981) seem to be largely accounted for by those who reported alcohol as a cause of symptoms. Possibly University staff tend to drink more or take a wider range of alcoholic drinks than the general public; red wine was mentioned by thirteen of Bender \& Matthews' subjects but by only one of ours. The response-rate in the University survey was rather low $(56 \%)$, and if persons with food intolerance were more disposed to return their questionnaires than others, the prevalence of food intolerance would have been overestimated. In general, however, the pattern is fairly similar in the two surveys, the 'worst' foods affecting up to $5 \%$ of subjects. It is, of course, likely that some of the reported adverse effects would not be confirmed by 'blind' challenge testing, as has been found by other investigators (May; 1976; Bock et al. 1978). It is also possible that some cases of food intolerance are not recognized as such by the subjects concerned.

Like Bender \& Matthews (1981), we found no association between food intolerance and an allergic history. Indeed, the plasma $\operatorname{IgE}$ (an objective index of allergic tendency) was significantly lower in food-intolerant women than in those without such symptoms. In the absence of a plausible hypothesis to suggest a protective effect of allergy against food intolerance this must presumably be attributed to chance. But it implies that true allergy is very unlikely to be the cause of food intolerance in the vast majority of cases.

\section{REFERENCES}

Bender, A. E. \& Matthews, D. R. (1981), Br, J. Nutr. 46, 403.

Bleumink, E. (1970). Wld Rev. Nut. Diet. 12, 505.

Bock, S. A., Lee, W-Y., Remigio, L. K. \& May, C. D. (1978). J. Allergy Clin. Immunol. $62,327$.

May, C. D. (1976). J. Allergy Clin. Immunol. 58, 520.

Merrett, T. G. \& Merrett, J. (1978). Clin. Allergy 8, 543. 